\title{
Editorial: Launching the Sixth Issue with a Strengthened Partnership with Shanghai International Library Forum
}

I am delighted to announce the launch of the sixth issue with a strengthened partnership between the IJoL and Shanghai International Library Forum (SILF). Four papers which were presented in the ninth SILF and published in its conference proceedings have been selected into this issue after extensive reviews and revisions. These papers include two Featured Articles and two Reports from the Field as follows:

Le at Pennsylvania State University examined the managerial and leadership attributes through a study on the library directors from the fourteen public and private universities in the Big Ten Academic Alliance.

Yi reviewed related literature and analyzed the usage data of Online Streaming Videos (OSV) databases at California Sate University of San Marcos. The findings indicate that the OSV collection is a valuable teaching and learning resource.

$\mathrm{Ma}$ and $\mathrm{Yu}$ reported their experience and observations of conducting real-time online library instructions to students enrolled in the distance education programs through a collaboration between Charles Sturt University in Hong Kong and the University of Hong Kong.

Xie at Dartmouth College Library discussed a special collection project on the Papers of Charles Daniel Tenney, including the discovery, digitization, publication and utilization. The author examined the value of librarians partnering with faculties and colleagues to promote digital humanities.

Beyond these SILF papers, there are three additional articles included in the section of Featured Articles. Chen, Shan, Li, Wang and Liu proposed an agglomerative-adapted partition approach for large-scale graphs based on the ontology structure and RDF data. The algorithm developed can be applied to the storage, data retrieval and semantic reasoning of large-scale RDF graphs.

Xiong et al. conducted a membership survey to all members of the Chinese American Librarians Association (CALA) to identify their awareness, perception and usage of the associations' policies and services. The results and findings have implications for CALA and other associations to build a stronger organization.

Nagra and López-Fitzsimmons introduced the organic learning in undergraduate library instructions, reference and research consultations based on the Association of College \& Research Libraries (ACRL) Information Literacy framework. They argue that the organic learning strategies and practices prepare undergraduate students for their academic success and lifelong learning. 
This issue also includes a news article by Feng reporting the ACRL 2019 conference held in Cleveland, $\mathrm{OH}$, US.

In the end, I would like to thank our authors, reviewers, editors and SILF organizers who have made significant contributions to this issue.

\section{Guoying Liu, University of Windsor}

